\title{
Assessment of Emotional Distress among Women Had Abortion
}

\author{
Saadya H. Humadee, $\mathrm{PhD} *$ \\ *Assistance Professor Department of nursing, Babel Technical Institute, Iraq.
}

\begin{abstract}
Objective: To assess the emotional distress following abortion.
Design: A descriptive analytic study.

Setting: Babel maternity- child hospital in Babylon governorate.

Population: A sample was fifty women who attended to maternity- child hospital during the period 15/5/201315/6/2013.

Methods: The mean with (SD) of age was $30.8 \pm(7.4)$ years experiencing emotional distress symptoms. A questionnaire format used for data collection was designed and constructed after reviewing related literatures and previous studies and used the perceived emotional distress inventory scale to assess the emotional distress for women and collected basic demographic data were also.

Main results: The study found that the highest percentage of age group was (32\%) of study sample their age group (23-27) years, the mean with SD. was $30.8 \pm 7.4$ years, (42\%) of study sample was institutes and college graduate and the highest percentage was (72\%) of study sample at (1-2) having abortion and the study found that the highest mean of score within item (2) was (2.24) refers to feel strained and the lowest mean of score within item (3) was (1.6) refers to feel distant from friends. the mean of score for all items are (1.91) and found that the statistical significant correlation between age, educational level and having abortions with the all items of perceived emotional distress inventory scale.

Conclusion: There was emotional distress following abortion among women so they need help for coping with their emotions by provide post-abortion counseling clinics and counseling services in community.

Key words: Assessment, the perceived emotional distress inventory scale, abortion.
\end{abstract}

\section{Introduction:}

Abortion can occur spontaneously, it usually called a miscarriage, or it can be purposely induced ${ }^{[1]}$. The number of abortions worldwide has remained stable in recent years, with 41.6 million having been performed in 2003 and 43.8 million having been performed in 2008. The abortion rate worldwide was 28 per 1000 women between 15 and 44 years of age, though it was 24 per 1000 women for developed countries and 29 per 1000 women for developing countries ${ }^{[2]}$. Abortion may have adverse effects on women's mental health. Most women will find it difficult to make the decision to have an abortion and many find the experience stressful, unpleasant and the most common emotional response after abortion is a profound of persistent feelings of sadness and regret ${ }^{[3]}$. The decision-making process may be stressful, even if the outcome is ultimately positive. Some women feel grief even though they know they made the right decision. this is a condition called "Post-Abortion Stress Syndrome ${ }^{[4]}$. In the United States alone 1,300,000 abortions occur annually. Almost everyone was directly or indirectly affected by abortions and even the second child did not alleviate the pain of her earlier loss. Some women have trouble bonding with their other children because of fear and guilt ${ }^{[5]}$. Later abortions harm women's mental health that make many women the abortion debate so heated ${ }^{[6]}$. One of the most prevalent outcome of abortion was shame and guilt that the mother suffer sometimes for years. This is the most common post abortion syndrome symptom. Because they believe they were doing something wrong, they had difficulty talking about it. Many women hide this secret. This self-protective measure is self-defeating, many of them are too ashamed to talk about it and lead that many women suffer from psychological disorders after having an abortion, so women need support and help to heal from the devastating effects of an abortion. Adolescents are more vulnerable to emotional and psychological issues after an abortion than older women . Adolescents who aborted pregnancy presented significantly greater prevalence of depression and anxiety than those who did not abort ${ }^{[7]}$. The current study assessed the emotional distress following abortion among women.

\section{Methodology:}

A descriptive analytic study conducted a non-probability sample assessed 50 women who attended to maternity- child hospital during the period 15/5/2013-15/6/2013. The mean with (SD) age of women were 30.8 \pm (7.4) years experiencing emotional distress symptoms. A questionnaire format used for data collection was designed and constructed after reviewing related literatures and previous studies and use the perceived emotional distress inventory scale for assess of emotional distress, the score: 0 for (not at all), 1 for (sometimes), 2 for (often), 3for (very much so) and basic demographic data also collected. 


\section{Results:}

The women who assessed had the highest percentage (32\%) of study sample their age group (23-27) years, the mean with SD. was $30.8 \pm 7.4$ years. (42\%) of study sample were institutes and college graduate while the lowest percentage (8\%) of them was illiterate. The highest percentage was (72\%) of study sample at (1-2) abortion while the lowest percentage (10\%) had (5-6) abortion as shown in table (1).

Table (1): Distribution of the Study Sample according to Demographic Characteristics.

$(\mathbf{n}=\mathbf{5 0})$

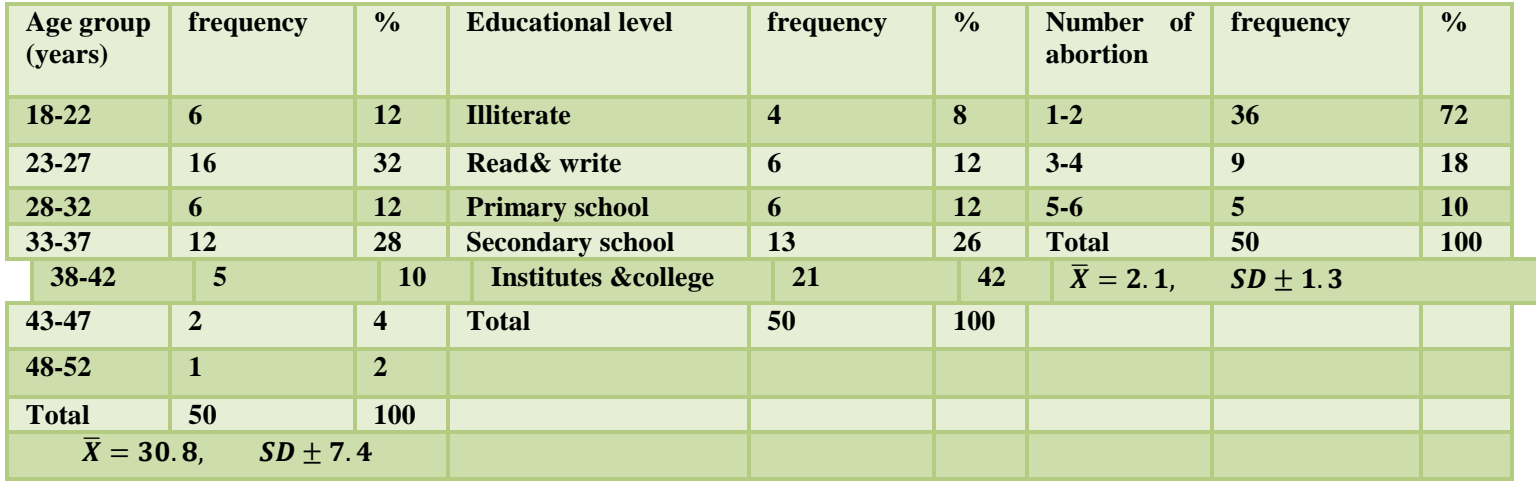

- Table (1) shows that the highest percentage of age group were (32\%) of study

sample their age group (23-27) years, the mean with SD. was $30.8 \pm 7.4$ years.

- Educational Level: (42\%) of study sample were institutes and college graduate while the lowest percentage ( $8 \%)$ of them was illiterate.

- Number of abortion: The highest percentage was $(72 \%)$ of study sample had(1- 2) abortion while the lowest percentage (10\%) had (5-6) abortion.

Table(2):The emotional distress following abortion among study ample.(n=50)

\begin{tabular}{|c|c|c|c|c|c|c|c|c|c|}
\hline Statements & $\begin{array}{l}\text { Not at } \\
\text { all } \\
\text { (0) }\end{array}$ & $\%$ & $\begin{array}{l}\text { Some } \\
\text { Times } \\
\text { (1) }\end{array}$ & $\%$ & $\begin{array}{l}\text { Often } \\
\text { (2) }\end{array}$ & $\%$ & $\begin{array}{l}\text { Very } \\
\text { Much so } \\
\text { (3) }\end{array}$ & $\%$ & $\bar{X}$ \\
\hline 1- I get easily irritated & 3 & 6 & 17 & 34 & 16 & 32 & 14 & 28 & 1.82 \\
\hline 2- I feel strained & 1 & 2 & 7 & 14 & 21 & 42 & 21 & 42 & 2.24 \\
\hline 3- I feel distant from my friends & 13 & 26 & 12 & 24 & 7 & 14 & 18 & 36 & 1.6 \\
\hline 4- I am angrier than I am willing to admit & 11 & 22 & 12 & 24 & 14 & 28 & 13 & 26 & 1.58 \\
\hline 5- I feel nervous & 4 & 8 & 8 & 16 & 15 & 30 & 23 & 46 & 2.14 \\
\hline 6- I feel confused and restless & 6 & 12 & 10 & 20 & 10 & 20 & 24 & 48 & 2.04 \\
\hline 7- I feel overwhelmed by "simple difficulties" & 8 & 16 & 14 & 28 & 15 & 30 & 13 & 26 & 1.66 \\
\hline 8- I worry that my condition will get worse & 7 & 14 & 6 & 12 & 15 & 30 & 22 & 44 & 2.04 \\
\hline 9- I am not enjoying the things I usually do for fun & 8 & 16 & 14 & 28 & 15 & 30 & 13 & 26 & 1.66 \\
\hline 10- I am losing hope in the fight against my illness & 12 & 36 & 8 & 16 & 11 & 22 & 19 & 38 & 1.74 \\
\hline 11- I "boil inside", but I try not to show it & 1 & 2 & 11 & 22 & 16 & 32 & 22 & 44 & 2.18 \\
\hline 12- I am losing faith in my medical treatment & 9 & 18 & 8 & 16 & 17 & 34 & 16 & 32 & 1.8 \\
\hline 13- I feel angry & 3 & 6 & 11 & 22 & 14 & 28 & 22 & 44 & 2.1 \\
\hline 14- I feel sad & 3 & 6 & 11 & 22 & 12 & 24 & 24 & 48 & 2.14 \\
\hline 15- I feel like a failure & 10 & 20 & 6 & 12 & 17 & 34 & 17 & 34 & 1.82 \\
\hline Total & & & & & & & & & 28.65 \\
\hline Mean & & & & & & & & & 1.91 \\
\hline
\end{tabular}

$*$ Cut off point $=1.5$

Table(2) shows that the highest mean of score within item (2) was (2.24) refers to I feel strained and the lowest mean of score within item (3) was (1.6) refers to I feel distant from my friends. The mean of score for all items are (1.91). 
Table(3): Person correlation between age, educational level and number of abortion with the perceived emotional distress inventory items. $(\mathrm{n}=\mathbf{5 0})$

\begin{tabular}{|c|c|c|c|}
\hline Statements & Age & Educational level & $\begin{array}{l}\text { Number of } \\
\text { abortions }\end{array}$ \\
\hline 1- I get easily irritated & $.036^{*}$ & .109 & $.000 * *$ \\
\hline 2- I feel strained & $.040 *$ & .765 & $.032 *$ \\
\hline 3- I feel distant from my friends & .577 & .122 & .240 \\
\hline 4- I am angrier than I am willing to admit & $.010^{*}$ & .578 & $.005 * *$ \\
\hline 5- I feel nervous & $.011 *$ & .763 & $.011^{*}$ \\
\hline 6- I feel confused and restless & .110 & .532 & $.005 * *$ \\
\hline 7- I feel overwhelmed by "simple difficulties" & $.025^{*}$ & .352 & $.016^{*}$ \\
\hline 8- I worry that my condition will get worse & .795 & .870 & $.014 *$ \\
\hline 9- I am not enjoying the things I usually do for fun & .154 & .214 & $.009 * *$ \\
\hline 10- I am losing hope in the fight against my illness & .895 & .517 & $.001 * *$ \\
\hline 11- I "boil inside", but I try not to show it & $.032 *$ & .656 & $.001 * *$ \\
\hline 12- I am losing faith in my medical treatment & .070 & .420 & $.000 * *$ \\
\hline 13- I feel angry & .253 & .568 & $.055^{*}$ \\
\hline 14- I feel sad & .959 & .639 & $.037 *$ \\
\hline 15- I feel like a failure & .889 & .747 & $.006 * *$ \\
\hline
\end{tabular}

\section{Sig.=significant}

** Person's correlation is significant at the 0.01 level(2-tailed).

\section{* Person's correlation is significant at the 0.05 level(2-tailed).}

Table(3) shows that the statistical significant correlation between age, educational level and number of abortion with the all items of perceived emotional distress inventory scale.

\section{Main findings:}

\section{Discussion:}

The study found that there was emotional distress following abortion among women and there was a statistical significant correlation between age, educational level and number of abortion with the all items of perceived emotional distress inventory scale. When assess the emotional distress following abortion among women by using the perceived emotional distress inventory scale, revealed that the abort women suffered from emotional distress, as shown in table (2).

The present study found that the women age with SD. was $30.8 \pm 7.4$ years. who had previous abortions suffering from emotional distress. A previous study showed that almost every women directly or indirectly affected by abortions $^{[6]}$.

Abortions percentage in 2008 were under age 15 (0.4\%), ages 15-17 (6.2\%), ages 18-19 (11\%), ages 20-24 (33.4\%), ages 25-29 (24.4\%), that agreed with finding of this study. Ages 30-34 (13.5\%), ages 35-39 (8.2\%), ages $40+(2.9 \%)$, more than $(57.8 \%)$ are performed on women between the ages of $20-29^{[7]}$.

And stated that the education level of the woman having an abortion in 2008: Non-graduate of high school was $(12.3 \%)$, High school graduate was $(28.3 \%)$, Some college was $(39.5 \%)$, Post-college graduate degree was $(19.9 \%)^{[7,8]}$. The study found that there was significant correlation between age, educational level and number of abortion with the perceived emotional distress inventory items, as shown in table (3).

Previous study stated that four factors are (age, level of education, socio-economic status and parity) were found to be significantly correlated related Psychological disorders which the most prevalent outcomes of abortion was shame and guilt that the mother suffer sometimes for years because they believe they are doing something wrong, they have difficulty talking about it so many women hide this secret ${ }^{[9]}$.

The task force studies indicate that some women experienced sadness, grief and feelings of loss following an abortion and some may experience, clinically significant disorders including depression and anxiety $^{[10]}$.

A study showed that 50-60\% of women undergoing induced abortion experienced some measure of emotional distress, classified as severe in $30 \%$ of cases ${ }^{[11]}$. Saddening experience because of male pressure on women to have an induced abortion had a significant, negative influence on women's psychological responses in the 2 years following the event ${ }^{[12]}$.

Robinson's criteria contrasting basic negative emotions related abortion were anger, rage, sorrow, grief frustration and disappointment ${ }^{[13]} .40-45 \%$ of women experience significant levels of anxiety and around $30 \%$ 
experience significant levels of depressive symptoms and emotional problems following abortion after a month ${ }^{[14]}$. The pressure from partner was significantly associated with more negative emotional reactions following an abortion $^{[12]}$.

A study reveals that the psychological trauma caused by a therapeutic abortion, the significant distress of the mothers accentuated by guilt feelings, persistent symptoms of depression and anxiety. Different reactions within the couple are perceived and can lead to marital conflict ${ }^{[15]}$.

Habitual abortions and unexplained habitual abortion can lead to grief, anxiety, distress and depression ${ }^{[16]}$. The highest quality studies found that women who had elective abortions experienced psychological distress and negative mental health sequel of abortion ${ }^{[17]}$.

The way of psychological responses to miscarriage and abortion differed during the five-year period after the event. Women who had undergone an abortion exhibited higher scores during the follow-up period for some outcomes ${ }^{[19,1]}$. This study agreed with these previous studies.

\section{Strengths and limitations:}

The strength of the study use of validated assessment tool and use of the perceived emotional distress inventory scale $^{[18]}$. I have limited the analysis to those who were have psychological and emotional problems due to other causes and factors.

\section{Conclusion:}

There was emotional distress following abortion among women so they need help for coping with their emotions.

\section{Disclosure of interests:}

The authors report no conflict of interest.

\section{Contribution to authorship:}

No contribution to authorship.

Details of ethics approval:

No details of ethics approval.

\section{Funding:}

there was no fund.

\section{Acknowledgement:}

A grateful acknowledgement and appreciation to all women who made this study possible.

\section{Recommendations:}

1- Psychological therapy should be offered following abortion.

2- Mental health outcomes of abortion must be used as a rationale for policy-making following abortion.

\section{References:}

[1]. Anne N B.; Torbjørn M.; Anne S B. and Øivind E.: The course of mental health after miscarriage and induced abortion: a longitudinal, five-year follow-up study Journal BMC Medicine ISSN: 17417015 Year: 2005 Volume: 3 Issue: 1 Pages: 18 Provider: BioMed Central. DOAJ Publisher: BioMed Central. http://www.biomedcentral.com/1741-7015/3/18

[2]. Guttmacher Institute: Facts on Investing in Family Planning and Maternal and Newborn Health November 2010. Retrieved 24 October 2011.

[3]. Templeton A.; Grimes D A.: A Request for Abortion. New England Journal of Medicine .365 (23): 2198-2204. December 8, 2011. doi:10.1056/NEJMcp1103639.

[4]. National Abortion Federation: what should I expect after abortion: EMOTIONS 2010.

[5]. Steinberg J R.: Later Abortions and Mental Health: Psychological Experiences of Women Having Later Abortions-A Critical Review of Research. May 2011. Women's Health Issues 21 (3): S44-S48.doi:10.1016/j.whi.2011.02.002. PMID 21530839.

[6]. Barnes S.: The Long Term Effects of Abortion on Women. February 10, 2009, Updated December 23, 2010.

[7]. Zulčić-Nakić V.; Pajević I.; Hasanović M.; Pavlović S. and Ljuca D.: Psychological problems sequalae in adolescents after artificial abortion. 2012 North American Society for Pediatric and Adolescent Gynecology. Published by Elsevier Inc. [PubMed - indexed for MEDLINE] . J Pediatr Adolesc Gynecol. 2012 Aug;25(4):241-7. doi: 10.1016/j.jpag.2011.12.072. Study was last updated on December 03, 2012.

[8]. Fleischmann R.: Sobering Statistics on Abortion. Clearly Caring Magazine-Home Edition, 1st Quarter 2011, Vol. 31, No. 1http://www.christianliferesources.com?9244

[9]. Fatoye FO.; Adeyemi AB. and Oladimeji BY.: Emotional distress and its correlates among Nigerian women in late pregnancy Obstetrics, 2004, Vol. 24, No. 5 , Pages 504-509 (doi:10.1080/01443610410001722518)

[10]. Major B.; Appelbaum M.; Beckman L.; Dutton MA.; Russo NF. and Kim I: APA Task Force Finds Single Abortion Not a Threat to Women's Mental Health. American Psychological Association. 12 August 2008. Retrieved 7 September 2011. (202) 336-6048

[11]. Wikipedia, the free encyclopedia: Emotional distress. This page was last modified on 11 November 2012 at 01:43. A Publication of Rachel's Vineyard Ministries.www.RachelsVineyard.org. 
[12]. Broen AN.; Moum T.; Bödtker AS. and Ekeberg O.: Reasons for induced abortion and their relation to women's emotional distress: a prospective, two-year follow-up study. General Hospital Psychiatry, Volume 27, Issue 1, Pages 36-43, January 2005. Received 24 May 2004; accepted 21 September 2004.

[13]. Wikipedia, the free encyclopedia :Contrasting and categorization of emotions. This page was last modified on 17 May 2013 at 09:17.

[14]. Bradshaw Z.; Slade P. : Clinical Psychology Review [2003, 23(7):929-958] (PMID:14624822)DOI: 10.1016/j.cpr.2003.09.001

[15]. Gaudet C.; Sejourne N.; Allard MA. adn Chabrol H.: Women and the painful experience of therapeutic abortion. Gynécologie Obstétrique \& Fertilité, Volume 36, Issue 5, May 2008, Pages 536-542, 2008 Elsevier Publisher: Elsevier Masson SAS DOI: 10.1016/j.gyobfe.2008.02.021 http://dx.doi.org.tiger.sempertool.dk/10.1016/j.gyobfe.2008.02.021, How to Cite or Link Using DOI

[16]. Schulz-Du B C.: Psychological Factors in habitual abortions Der Gynäkologe. ISSN: 00175994 Year: 2009 Volume: 42 Issue: 1 Pages: 35-38 Provider: Springer Publisher: Springer DOI: 10.1007/s00129-008-2230-9 Not logged in Iraqi Virtual Science Library (3000135768) 78.111.165.165

[17]. Charles VE.; Polis CB.; Sridhara SK. and Blum RW.: Abortion and long-term mental health outcomes: a systematic review of the evidence :Journal Contraception ISSN: 00107824 Year: 2008 Volume: 78 Issue: 6 Pages: 436-450 Provider: Elsevier Publisher: Elsevier DOI: 10.1016/j.contraception.2008.07.005 http://dx.doi.org.tiger.sempertool.dk/10.1016/j.contraception.2008.07.005, How to Cite or Link Using DOI

[18]. Manolete SM: Perceived Emotional Distress Inventory, University of South Florida

[19]. Broen AN, Moum T, Bodtker AS, Ekeberg O: Reasons for induced abortion and their relation to women's emotional distress: a prospective, two-year follow-up study. Gen Hosp Psychiatry 2005, 27:36-43. This page was last modified on 13 September 2013, at $16: 26$. 